\title{
PENELITIAN SEJARAH RELASI PUBLIK: KONSEP DAN METODOLOGI
}

\author{
Astri Yogatama \\ Program Studi Ilmu Komunikasi, Universitas Kristen Petra \\ Jl. Siwalankerto 121-131, Surabaya 60236, INDONESIA \\ Email: astri@petra.ac.id
}

\begin{abstract}
ABSTRAK
Para sejarawan menggunakan penelitian sejarah untuk merekam praktik relasi publik yang pernah terjadi dalam berbagai konteks dari masa ke masa atau fokus pada kejadian tertentu. Namun demikian jumlah penelitian sejarah relasi publik tidak berkembang sepesat kebutuhan akan pengembangan konsep relasi publik maupun strategi komunikasinya, maupun jika dibandingkan dengan perkembangan ilmu sosial lainnya. Untuk itu dipandang perlu penelitian sejarah diaktifkan dalam ranah relasi publik, melalui beberapa tahapan dalam metodologinya. Tahapan itu meliputi penetapan fenomena relasi publik, perumusan masalah, penetapan hipotesa, penentuan metode penelitian, pengumpulan data, uji validitas dan reliabilitas, analisa data dan penyusunan laporan. Di balik keterbatasan penelitian sejarah dalam hal pengumpulan data primer dan subyektivitas sejarawan, diharapkan penelitian sejarah akan memberikan dasar pengembangan konsep baru dalam dunia relasi publik dan strategi komunikasi yang lebih komprehensif.
\end{abstract}

Kata kunci: Penelitian Sejarah, Relasi Publik, Metodologi.

\begin{abstract}
The urgency of historical research has arisen in public relations related to limited documentations of the history of public relations trough periods or on certain occurances. It places the development of public relations as science in the limped, compare to other social sciences. Historical research of past events is a methodology to support historians in collecting and analysing history scientifically. Procedures of the methodology are deciding public relations phenomenon, research questions, hypotheses, method, data collection, doing validity and reliability test, data analysis and making research report. Despite of the limitations of the methodology, it will highly contribute to the development of public relations as science and also strategic communication comprehensivelly.
\end{abstract}

Keywords: Historical Research, Public Relations, Methodology.

\section{PENDAhUluan}

Relasi publik adalah sebuah cabang ilmu yang baru berumur sekitar satu abad sejak pertama kali dikukuhkan secara ilmiah oleh Ivy Lee maupun Edward Bernays. Walau demikian menelusuri sejarah relasi publik tidak tergolong mudah sekalipun usianya belum setua ilmu sosial lainnya. Relasi publik dalam bingkai masa lalu telah dituliskan secara terbatas oleh beberapa ilmuwan / praktisi barat dan sangat sedikit dieksplorasi oleh praktisi/ilmuwan timur dan dalam konteks tulisan ini adalah Indonesia. Sekalipun demikian praktik relasi publik telah dilakukan dan dikenali dalam bentuk propaganda maupun publisitas sejak jaman sebelum kemerdekaan Indonesia (Dhani, Lee, Fitch 2009, p.22). Istilah praktisi relasi publik atau public relations officer belum dikenal masa itu sehingga lebih menyulitkan dokumentasi tentang aktivitas/peran/fungsi relasi publik yang pernah terjadi. Kelangkaan tulisan sejarah berkaitan dengan tidak populernya penelitian sejarah (historical research) di dunia relasi publik dibanding dengan metode penelitian lainnya seperti survey, polling, maupun studi kasus (Daymon and Holloway, 2011, p. 189). Manfaat melakukan studi sejarah belum banyak dipertimbangkan oleh praktisi maupun ilmuwan relasi publik sebagai bagian dari komunikasi strategis. Dalam penyusunan strategi relasi publik, sejarah dapat memberikan gambaran tentang keberhasilan/ kegagalan aktivitas terdahulu, metode yang pernah digunakan dalam praktik, lalu secara khusus untuk dunia relasi publik mendapatkan pemetaan aktivitas relasi publik dan kaitannya dengan berbagai bidang ilmu lain yang secara praktis memang senantiasa berkolaborasi dengan dunia relasi publik. Politik, sosial, budaya, ekonomi dan bidang ilmu lain tercatat memiliki kaitan dengan relasi publik walau belum terdokumentasi dengan baik. Akibat lainnya adalah perkembangan teori relasi publik menjadi lamban dibanding berbagai teori sosial. Kebutuhan akan dokumentasi sejarah relasi publik penting bagi perkembangan profesi ini, lebih lagi mengetahui bahwa relasi publik telah memberikan kontribusi besar bagi bidang sosial lainnya (Vos, 2011, p.119) khususnya di Indonesia. 


\section{TINJAUAN PUSTAKA}

\subsection{Penelitian Sejarah}

Sejarah secara harafiah berasal dari bahasa Yunani historia yang berarti pengetahuan yang didapat dari penelitian. Dalam pengertian yang lebih luas sejarah adalah rekaman pengetahuan tentang masa lalu. Rekaman peristiwa dapat diwujudkan dalam bentuk tulisan manual (manuskrip) maupun simbol, cetakan, rekaman suara, rekaman gambar, atau format digital untuk sejarah yang dituliskan di era media baru. Batasan waktu dan kerangka logika bersifat subyektif karena bergantung pada perspektif sejarawan maupun kepentingan penulisan sejarah. Perspektif sejarawan merupakan bagian identitas diri/sosial yang mempengaruhi cara dia melihat sebuah peristiwa di masa lalu, termasuk menentukan paradigma sosial saat proses penulisan sejarah secara ilmiah dilakukan. Gardiner (1974) mengatakan bahwa batasan waktu dapat dimaknai berbeda oleh beberapa sejarawan. Dalam perkembangan penelitian sejarah, waktu dapat dipandang sebagai: bagian dari proses kehidupan yang berjalan linier atau sirkular, ditentukan berdasarkan prinsip atau hukum ilmu tertentu, merupakan pola utuh dari sebuah sistem, ataupun sebuah babak dari peristiwa yang sengaja/tidak sengaja diciptakan. Dari berbagai pemaknaan terhadap unsur waktu dalam sejarah, maka karya para sejarawan menjadi kompleks karena mereka dapat mengembangkan berbagai pola tulisan sejarah berdasar sebuah/beberapa peristiwa yang terjadi pada kurun waktu dan lokus yang sama. Sebagai contoh, sejarah relasi publik Indonesia yang diawali tahun 1900-an, telah ditulis dengan menggunakan beberapa sudut pandang: aktivitas diplomasi publik (Yudarwati, 2014), aktivitas propaganda (Dhani, Lee, and Fitch, 2015), relasi publik pemerintah (Suprawoto, 2018), dan popularitas profesi relasi publik (Simorangkir, 2009). Sedangkan Daymon dan Holloway (2011) memilah fokus penulisan sejarah pada rekonstruksi peran komunikasi pada sebuah kejadian sejarah misalnya "The Histories of British Public Relations as a Professional Practice (L'Etang 2004) dan sejarah pemikiran/ide/bidang studi/konsep misalnya "A Study of Public Relations Historians and their Histories (Pearson, 2009 dalam Daymon dan Holloway, 2011). Sejarawan selanjutnya perlu mengkaitkan kurun waktu yang ditentukan dengan pertanyaan riset agar agar analisis sejarah menjadi kontekstual dan beralasan logis.

\subsection{Penelitian Sejarah dalam Ranah Relasi Publik}

Relasi publik adalah sebentuk komunikasi strategis yang berkembang cukup pesat di tengah dinamika sosio-politik abad ke-17 (Cutlip, 1995) hingga saat ini. Wujud dari aktivitas maupun peran relasi publik tidak serta merta muncul dengan label "relasi publik" hingga kemudian Ivy L.Lee maupun Bernays E mengukuhkan istilah relasi publik melalui publikasi/ autobiografi (Bernays E., 1923). Popularitas Lee maupun Bernays secara internasional, membawa konsekwensi terhadap sejarah relasi publik internasional yang sangat kental nuansa kondisi Amerika tahun 1900-an. Selain itu asosiasi relasi publik yang telah berdiri, digawangi Amerika Serikat, Inggris maupun Belanda. Kenyataan ini menimbulkan kesan bahwa kerja relasi publik hanya terjadi di negara barat. Akibatnya teori relasi publik didasarkan pada situasi ekonomi, sosial, budaya, politik negara-negara sudah berkembang. Implementasi teori-teori tersebut di negara lainnya tentunya memerlukan penyesuaian. Hal ini yang menjadi salah satu alasan penelitian sejarah relasi publik yang bersifat nasional menjadi penting. Secara singkat Bates merunutkan sejarah relasi publik internasional seperti pada tabel 1 .

Tabel 1. Sejarah Umum Relasi Publik

\begin{tabular}{|c|c|}
\hline Waktu & Kejadian Penting \\
\hline 1900 & $\begin{array}{l}\text { Biro Publisitas pertama berdiri di Boston (di } \\
\text { Amerika) }\end{array}$ \\
\hline 1904 & $\begin{array}{l}\text { Ivy L. Lee menjadi penasihat relasi publik } \\
\text { pertama }\end{array}$ \\
\hline 1913 & $\begin{array}{l}\text { Ludlow Massacre membuat value of corporate } \\
\text { public relations }\end{array}$ \\
\hline 1923 & $\begin{array}{l}\text { Edward L. Bernays menerbitkan "Crystallizing } \\
\text { Public Opinion" sebagai buku pertama tentang } \\
\text { profesi relasi publik }\end{array}$ \\
\hline 1929 & $\begin{array}{l}\text { Bernays membuat tahapan "Torches of Free- } \\
\text { dom" march sebagai bagian dari promosi rokok }\end{array}$ \\
\hline 1948 & $\begin{array}{l}\text { Public Relations Society of America (PRSA) } \\
\text { dididirikan }\end{array}$ \\
\hline 1950 & $\begin{array}{l}\text { PRSA Code of Professional Standards diadopsi } \\
\text { oleh praktisi relasi publik }\end{array}$ \\
\hline 1955 & $\begin{array}{l}\text { International Public Relations Association } \\
\text { (IPRA) didirikan }\end{array}$ \\
\hline 1965 & $\begin{array}{l}\text { PRSA membakukan akreditasi profesi relasi } \\
\text { publik }\end{array}$ \\
\hline 1970 & $\begin{array}{l}\text { International Association of Business Commu- } \\
\text { nicators (IABC) didirikan }\end{array}$ \\
\hline 1989 & $\begin{array}{l}\text { Krisis di Exxon Valdez muncul sebagai kasus } \\
\text { relasi publik yang cukup berat }\end{array}$ \\
\hline 1998 & Dewan relasi publik korporat didirikan \\
\hline 2000 & $\begin{array}{l}\text { PRSA Code of Ethics direvisi dan menjadi } \\
\text { panduan }\end{array}$ \\
\hline 2002 & $\begin{array}{l}\text { PRSA mengumumkan akreditasi bagi seluruh } \\
\text { pekerja relasi publik sebagai standar untuk } \\
\text { praktik }\end{array}$ \\
\hline
\end{tabular}

Dalam kurun waktu yang singkat, peran relasi publik mulai dirasakan oleh korporat maupun pemerintah, meskipun belum terdokumentasi secara detail, hanya secara umum berdasarkan autobiografi maupun beberapa kasus-kasus pelik di bidang bisnis atau 
pemerintahan. Scott M.Cutlip merupakan salah satu penulis sejarah relasi publik yang cukup banyak dikutip penulis sejarah relasi publik lainnya. Dua publikasinya "Public Relations: The Unseen Power" dan "Public Relations History: From the 17th Century to the $20^{\text {th }}$ Century" adalah rujukan tentang awal mula munculnya disiplin ilmu maupun profesi relasi publik di dunia.

\subsection{Dokuman Sejarah Relasi Publik dalam Kon- teks Ekonomi, Sosial, Budaya dan Politik}

Penulis sejarah relasi publik lainnya, L'etang (2008) menyebutkan bahwa selain yang telah dikemukakan oleh Cutlip tentang pentingnya peran sejarawan relasi publik dalam menulis konsep/ide relasi publik dan praktiknya, sejarawan relasi publik perlu juga mengaitkan peran individu, organisasi dan level-level sosial (dalam masyarakat/publik) dalam penulisan sejarah relasi publik. Keberagaman hubungan publik dan praktik relasi publik belum dieksplorasi, dicatat dengan baik dan teranalisis sebagai bagian dari kerja / fungsi / model / peran / proses relasi publik. Sehingga akibatnya pamor relasi publik menjadi minor dibanding peran dan fungsi manajemen lainnya dalam dinamika perkembangan suatu organisasi atau korporat atau lebih luas lagi di tengah masyarakat/ bangsa. Akibat lainnya adalah lepasnya konteks kerja relasi publik dengan institusi sosial maupun isu sosial dalam masyarakat, misalnya keterkaitannya dengan budaya, media massa, pendidikan dan sebagainya. Kesulitan menemukan tulisan sejarah relasi publik dalam beragam konteks sosial, ekonomi, politik, budaya atau lainnya mendorong beberapa sejarawan memulai untuk mengkaitkan relasi publik dengan isu disiplin ilmu lainnya terlihat pada tabel 2 .

Sekelumit tulisan sejarah dalam tabel di atas menunjukkan dengan pasti bahwa praktisi relasi publik mampu menyusun strategi komunikasi yang berkekuatan tinggi dalam menggerakkan bidang sosial lain. Bagian dari sejarah Amerika yang ditulis oleh Terrence H. Witkowski menunjukkan bahwa sebuah poster yang dirancang sebagai produk aktivitas relasi publik, mempopulerkan gaya hidup sederhana paksa perang dunia ke-2 dapat mengarahkan aktivitas konsumsi masyarakat Amerika saat itu. Witkowski berhasil menarik garis penghubung antara relasi publik dengan sektor ekonomi, sosial budaya dan politik pada masa perang dingin.

\section{METODOLOGI PENELITIAN}

Metodologi adalah sebuah prosedur penelitian yang wajib dilakukan peneliti (Glesne, 2011). Sedangkan metode adalah cara mengumpulkan dan menganalisa data. Penelitian sejarah sebagai sebuah metodologi penelitian dipergunakan guna menelusuri dan menulis

Tabel 2. Publikasi Sejarah Relasi Publik dalam Konteks Ekonomi, Sosial, Budaya dan Politik

\begin{tabular}{|c|c|c|c|}
\hline Peneliti & Judul Publikasi & Isi Publikasi & Konteks \\
\hline$\overline{\text { Karen S. Miller }}$ & $\begin{array}{l}\text { Amplyfying the Voice of Business: Hill } \\
\text { and Knowlton's Influence on Political, } \\
\text { Public, and Media Discourse in Postwar } \\
\text { America }\end{array}$ & $\begin{array}{l}\text { Praktik relasi publik dan penyusunan } \\
\text { strategi komunikasi korporat yang } \\
\text { dilakukan oleh John W. Hill bersama } \\
\text { partnernya Don Knowlton dalam } \\
\text { mengatasi kasus-kasus perusahaan raksasa } \\
\text { dalam masa krisis atau konflik dengan } \\
\text { publik internal maupun eksternalnya. }\end{array}$ & Politik \\
\hline Marvin N.Olasky & $\begin{array}{l}\text { Corporate Public Relations : A New } \\
\text { Historical Perspectiv }\end{array}$ & $\begin{array}{l}\text { Sejarah bidang relasi publik, disertai } \\
\text { kasus-kasus khusus dan kritik dari tokoh } \\
\text { relasi publik seperti Ivy Lee dan Edward } \\
\text { Bernays. Buku ini menyertakan } \\
\text { penjelasan tentang peran kerja relasi } \\
\text { publik korporat dalam mempengaruhi } \\
\text { kebijakan ekonomi dan politik sebuah } \\
\text { negara. }\end{array}$ & $\begin{array}{l}\text { Ekonomi, } \\
\text { Politik }\end{array}$ \\
\hline Richard S. Tedlow & $\begin{array}{l}\text { Keeping the Corporate Image : Public } \\
\text { Relations and Business 1900-1950 }\end{array}$ & $\begin{array}{l}\text { Evolusi pekerjaan relasi publik dari 1900- } \\
1950 \text { dan kaitannya dengan praktek bisnis } \\
\text { di Amerika }\end{array}$ & Ekonomi \\
\hline Terrence H. Witkowski & $\begin{array}{l}\text { World War II Poster Campaigns : } \\
\text { Preaching Frugality to American } \\
\text { Consumers }\end{array}$ & $\begin{array}{l}\text { Implementasi, produk publikasi dan } \\
\text { dampak dari poster yang berisi ajakan } \\
\text { pemerintah kepada masyarakat untuk } \\
\text { hidup sederhana di masa perang dunia ke- } \\
2\end{array}$ & $\begin{array}{l}\text { Sosial, Politik. } \\
\text { Budaya }\end{array}$ \\
\hline
\end{tabular}

(Sumber: L'Etang, 2008, p.321) 
sejarah secara sistematis berdasar prinsip penulisan ilmiah. Penelitian sejarah dapat diteliti dengan paradigma kuantitatif, kualitatif atau perpaduan keduanya, tergantung pada tujuan penelitian, kualitas data dan ketersediaan sumber. Metodologi penelitian sejarah menurut Given (2008) dikembangkan melalui beberapa tahap, yaitu identifikasi fenomena, perumusan masalah, penetapan hipotesa, penetapan metode penelitian, pengumpulan data, uji validitas dan reliabilitas, dan penulisan laporan penelitian.

\subsection{Identifikasi Fenomena}

Fenomena yang dimaksud di sini adalah fenomena komunikasi pada ranah relasi publik. Ranah relasi publik ini mencakup beberapa aspek semisal fungsi, peran, model, strategi dan aspek lain di dalamnya. Penetapan fenomena dapat dipertajam melalui pengayaan dari literatur terkait, menjelajah ide terkini tentang fenomena yang akan diteliti, dan menyelaraskan dengan minat utama peneliti. Fenomena ini dapat berkaitan dengan teori relasi publik tertentu, sehingga di dalamnya akan terdapat konsep-konsep yang mendukung terbentuknya teori yang dimaksud. Misalnya teori Persuasi, di dalamnya terdapat konsep persuasi. Fenomena, teori dan konsep kemudian mendasari terbentuknya pertanyaan riset.

\subsection{Perumusan Masalah}

Pertanyaan riset harus dibuat sejelas mungkin dan ditulis dalam bentuk eksploratori (L'Etang, 2008). Berdasarkan pedoman tersebut Daymond dan Holloway (2011) memberikan beberapa ide rumusan masalah:

a. How did public relations emerge in the AsiaPacific region and why?

b. What role did public relations play in the global Free Tibet campaign prior to the Olympic Games? Why and How?

c. What has been the relationship between advertising and power in the eastern European states, especially during the communist era?

d. Why and how did IBM set up internal communications function?

e. How has the concept of "public opinion" been employed by public relations and marketing scholars through the twentieth century?

f. How and why did the British publicist Max Clifford achieve public notoriety?

g. When did product placement on television as a marketing communications strategy emerge? Where and why?

(p.192)

\subsection{Penetapan Hipotesa}

Hipotesa ditetapkan untuk penelitian dengan paradigma kuantitatif. Penelitian sejarah umumnya menggunakan paduan paradigma kuantitatif dan kualitatif. Mengembangkan hipotesa atau rumusan masalah serta teori terkait untuk mengarahkan teknik pengumpulan data serta interpretasi hasil penelitian.

\subsection{Metode Penelitian}

Dalam implementasi penelitian sejarah, penetapan jenis data dan caranya bergantung pada metode penelitian yang dipergunakan. Penelitian sejarah sendiri memanfaatkan beberapa jenis metode penelitian (L'Etang, 2008; Daymon and Hallaway, 2011) sebagai berikut:
a. Cliometric
b. Metode oral history
c. Autobiography narrative
d. Life history
e. Qualitative case study
f. Qualitative content analysis
g. Discourse analysis

\subsection{Pengumpulan Data}

Penelusuran dan koleksi dilakukan secara bertahap. Data yang dikumpulkan dapat bersumber dari data primer/sumber pertama yang berkaitan dengan fenomena penelitian, maupun data sekunder. Data primer berupa hasil wawancara narasumber (orang) inti, dokumen asli, surat, karya seni, tulisan, musik, catatan observasi, catatan harian dan foto atau bukti otentik lainnya. Jika narasumber inti telah meninggal, maka memoir yang ditulis pribadi oleh narasumber dapat menjadi data primer. Data sekunder dapat berupa surat, catatan harian maupun tulisan / rekaman dalam bentuk apapun yang tidak dibuat oleh narasumber inti/saksi mata/dengar secara langsung di saat fenomena penelitian terjadi. Sumber sekunder ini sekalipun bukan dibuat oleh narasumber inti, namun diproduksi oleh orang yang mengenal secara baik dan dapat ditriangulasi dengan data-data lain (primer/ sekunder) untuk menentukan keabsahannya sebagai bagian dari data penelitian. L'Etang (2008) mengingatkan teknik pengumpulan data dan penulisan sejarah didasari oleh asumsi tentang peran, ruang lingkup dan tujuan sejarah ditulis. Ketiga hal tersebut akan membantu sejarawan menghadapi dinamika data dalam proses pengumpulan. Kemungkinan penambahan data dapat terjadi dalam praktik di lapangan. Hal tersebut harus dibatasi dengan 3 pedoman pengumpulan data di atas, supaya tetap ada fokus dalam penulisan sejarah. Pengumpulan data dihentikan jika data sudah bersifat jenuh (saturated). 


\subsection{Uji Validitas dan Reliabilitas Data}

Sejarawan wajib melakukan cek ulang terhadap seluruh data yang telah terkumpul yang diikuti dengan uji validitas dan reliabilitas data. Bila data telah valid dan reliabel maka dilakukan analisis data. Validitas data diuji melalui uji umur dokumen yang dipergunakan sebagai sumber data dan uji konsistensi kebenaran informasi melalui uji silang dari berbagai data yang dikumpulkan (triangulasi data). Sedangkan reliabilitas data dikaitkan dengan membebaskan data dari asumsi-asumsi pribadi peneliti. Given (2008) memberikan contoh tentang penggunaan istilah-istilah khusus seperti aborsi yang pada masa lalu belum diaplikasikan, sehingga tidak mungkin menggunakan istilah tersebut dalam penulisan sejarah dimana dia belum dikenal. Data yang reliabel dihasilkan dari koleksi data yang dikumpulkan secara kritis (mempertimbangkan sisi positif/negatif data dikumpulkan), menulis dengan akurat bila ada data yang hilang, dan menyadari keterbatasan perspektif (peneliti)dalam pengumpulan data.

\subsection{Penulisan Analisis dan Laporan Penelitian}

Analisis dan laporan penelitian mencakup temuan sejarawan atas data, dimana temuan diintrepretasi dan didukung oleh bukti-bukti untuk memberikan contoh dari fenomena yang terdapat pada rumusan masalah. Sekalipun pada umumnya sejarawan akan mendapati ketidaklengkapan data, perlu dilakukan interpretasi kritis terhadap ketiadaan maupun ketersediaan data. Sejarawan wajib mengungkapkan kontribusi signifikan tulisan sejarah pada masyarakat kontemporer masa kini. L'Etang (2008) memberikan catatan pada bagian interpretasi data, dimana sejarawan diharap melakukan penulisan narasi yang refleksif. Artinya di sini tulisan tersebut akan mencerminkan sudut pandang peneliti misalnya seorang feminist atau Marxist atau Posmodernist atau lainnya. Produksi sejarah oleh seorang sejarawan tidak akan sama dengan produksi sejarawan lainnya. Daymon dan Holloway 2011) memberikan petunjuk bentuk narasi/cerita sejarah dapat dianalisis dan disusun berdasar:

a. Urutan waktu,

b. Urutan topik,

c. Tatanan geografi,

d. Tatanan struktur sosial (kelas, gender, politik, ekonomi),

e. Tatanan kekuasaan,

f. Tahapan konflik, dan sebagainya. (p.195)

Tahapan akhir ini ditutup dengan penulisan kesimpulan penelitian, sumber pustaka, catatan kaki tentang asal data. Kelengkapan bagian kelima ini menunjang proses pembuktian validitas dan reliabilitas data yang dipergunakan.

\section{MANFAAT DAN KETERBATASAN PENE- LITIAN SEJARAH}

\subsection{Manfaat}

Pemahaman akan masa lalu akan membantu sejarawan atau siapa pun untuk memahami kejadian masa kini dengan lebih kontekstual dan berdasar ( Given, 2008).

Sejarah mencatat peristiwa sebelum dan sesudah kasus-kasus terjadi, sehingga pembaca dapat menganalisis dengan komprehensif sebuah/rangkaian peristiwa atau menjadikan keberhasilan/kegagalan penanganan kasus-kasus tersebut sebagai komparasi atau rekomendasi untuk mengatasi kasus di masa kini. Selanjutnya ide-ide, konsep-konsep, maupun teoriteori baru sangat mungkin dimunculkan dari analisis sejarah. Bahkan ketika sejarah relasi publik dikaitkan dengan bidang ilmu sosial lain, maka da kemungkinan munculnya teori sosial baru di luar ranah relasi publik.

\subsection{Keterbatasan}

Terdapat dua keterbatasan utama dalam penelitian sejarah, antara lain:

a. Keberadaan data primer

Data primer merupakan data yang sangat berharga dalam segala bentuk pendekatan maupun metode penelitian. Semakin lengkap data primer sesuai kebutuhan, maka validitas dan reliabilitas data dapat dipertanggungjawabkan oleh peneliti. Hal ini menjadi tantangan besar bagi sejarawan mengingat data primer baik narasumber utama maupun rekaman dokumen pendukung kerapkali punah oleh karena faktor usia atau masyarakat yang diteliti tidak memiliki budaya tulis/dokumentasi. Proses validasi dan pengukuran reliabilitas data sekunder kemudian menjadi pekerjaan rumah yang rumit karena sejarawan harus menemukan bukti keterkaitan data-data tersebut dengan data primer sebelumnya. Proses penggalian, validasi dan pengukuran reliabilitas ini yang akan memakan waktu cukup lama dan berulang-ulang sampai data dikatakan valid dan reliabel untuk dilanjutkan ke proses koding, klasifikasi, penghitungan statistik hingga interpretasi sebelum analisis akhir dilakukan.

b. Interpretasi masa lalu oleh peneliti masa kini berkaitan dengan keterbatasan peneliti dalam menye- 
lami pengalaman yang tak dialami secara pribadi. Ketajaman interpretasi sejarawan diuji melalui validitas dan reliabilitas data. Namun demikian hasil akhir dari sejarah tidak bersifat bebas nilai sepenuhnya, karena identitas sosial sejarawan memberikan kontribusi terhadap interpretasi. Hal ini selayaknya dianggap sebagai sebuah cara yang memberikan kekayaan pada interpretasi sejarah, ketimbang kekurangan penelitian sejarah. Seperti sejarah itu sendiri dialami oleh beragam individu yang memiliki interpretasi yang berbeda terhadap peristiwa yang mereka alami bersama-sama. Maka jika ditarik garis antara masa lalu dan masa kini, subjektifitas adalah sebuah keabsahan yang patut untuk dihargai sebagai dari realitas kehidupan.

\section{KESIMPULAN}

Penelitian sejarah relasi publik tidak hanya melulu tentang keberadaan relasi publik dari masa ke masa, namun perlu juga mengkaitkan praktik relasi publik dengan unsur sosial lainnya. Praktik relasi publik selalu berkaitan dengan praktik kehidupan masyarakat, struktur maupun pranata sosialnya. Sehingga topik-topik sejarah relasi publik dapat ditempatkan pada posisi yang saling bersinergi dengan topik kelas, gender, politik, ekonomi, pemerintahan, militer, keuangan, olahraga, seni, agama, budaya dan lain sebagainya. Demikian banyaknya praktik relasi publik di Indonesia yang dapat digali lebih lanjut dengan pendekatan sejarah, yang kemudian tentunya diharapkan akan memperkaya kazanah teori relasi publik. Pemanfaatan kerangka metodologis penelitian sejarah akan membantu pengembangan konsep, bahkan mampu melahirkan konsep-konsep baru dalam dunia relasi publik. Akhir sebuah penelitian sejarah adalah awal penulisan sejarah lainnya dan demikian selanjutnya.

\section{DAFTAR PUSTAKA}

Bates, D. 2006. Mini-me History: Public Relations from the Dawn of Civilization. Institute for Public Relations.
Bernays, E. 1923. Crystallizing Public Opinion, Liveright Publishing Corporation. New York.

Cutlip, S.M. 1995. Public Relations History: From the $17^{\text {th }}$ to the $20^{\text {th }}$ Century. Routledge.

Daymon, C. and Holloway, I. 2011. Qualitative Research Methods in Public Relations and Marketing Communications, Routledge. $2^{\text {nd }}$ edition.

Dhani, R., Lee, T., and Fitch, K. 2015. Political Public Relations in Indonesia: A History of Propaganda and Democracy. Asia Pacific Public Relations Journal.Vol. 16. No.1.

Gardiner, P. (Ed.) 1974. The Philosophy of History. Oxford University Press. Oxford.

Given, L.M. 2008. The Sage Encyclopedia of Qualitative Research Methods. Sage Publication.

Glesne, C. 2011. Becoming Qualitative Researchers. Pearson.

Joseph, Brian and Janda, Richard (Ed). 2008. The Handbook of Historical Linguistics. Blackwell Publishing. 2008.

L'Etang, J. 2004. Public Relations in Britain: A History of Professional Practice in the 20th Century. Lawrence Erlbaum Associates. Mahwah. NJ.

L'Etang, J.2008. Writing PR history: issues, methods and politics. Journal of Communication Management. Vol 12 No.4. pp 319-335

Simorangkir, D.N. 2009. Public Relations in Indonesia: History, Status, and Popular (mis) Perceptions. Saarbruecken. Lambert Academic Publishing.

Suprawoto. 2018. Government Public Relations: Perkembangan dan Praktik di Indonesia. Kencana. Prenada Media Group.

Vos, Tim P. 2011. Explaining the Origin of Public Relations: Logics of Historical Explanation. Journal of Public Relations Research. 23:2. 119140. DOI: 10.1080/1062726X.2010.504793

Yudarwati, G.A. 2014. Indonesia. In Watson, Tim (Ed). 2014. Asian Perspective on the Development of Public Relations: Other Voices. Palgrave Macmillan. 